\title{
La Investigación con Relatos de Vida: Pistas y Opciones del Diseño Metodológico
}

\section{Research with Life Stories: Clues and Options of the Methodological Design}

\author{
Marcela Cornejo, Francisca Mendoza y Rodrigo C. Rojas \\ Pontificia Universidad Católica de Chile
}

\begin{abstract}
En la investigación en ciencias sociales, la utilización del relato de vida ha mostrado importantes desarrollos, permitiendo articular significados subjetivos de experiencias y prácticas sociales. Son variados los trabajos que muestran resultados de investigaciones, así como variados aquéllos que discuten esta particular forma de concebir y articular conceptualmente las dimensiones subjetiva y social. La literatura sin embargo, ha soslayado aspectos del proceso de diseño e implementación de una investigación con relatos de vida. Este artículo intenta visibilizar estos aspectos, a la luz de las premisas que sustentan la investigación desde un enfoque biográfico. Se presenta un dispositivo de trabajo implementado en investigaciones realizadas, discutiendo a partir de él las opciones metodológicas tomadas, sugiriendo modos de abordar investigaciones con relatos de vida.
\end{abstract}

Palabras clave: relatos de vida; enfoque biográfico; investigación cualitativa; opciones metodológicas.

In social sciences research, the use of life stories has developed greatly allowing for the articulation of subjective meanings of social practices and experiences. There are several studies that show their findings as there is a variety of such pieces of research that discuss this particular way of conceptually conceiving and articulating subjective and social dimensions. The literature has, however, avoided analyzing aspects of the process of design and implementation of research based on life stories. In this paper there is an attempt to bring these aspects to the forefront, in light of the premises that underlie research from a biographical approach. A working device applied in previous research is presented, with discussion on methodological decisions and suggestions on how to approach research on life stories.

Keywords: life story; biographical approach; qualitative research; methodological options.

Los textos sobre investigación con relatos de vida (Demazière \& Dubar, 1997; Kornblit, 2004; Santamarina \& Marinas, 1993) no incluyen en general aspectos puntuales referidos al proceso de implementación de una investigación con relatos, en cuanto al diseño del dispositivo de investigación, a decisiones metodológicas sobre cuántos y a quiénes solicitar su relato, ni a cómo conducir las entrevistas, ni con qué frecuencia realizarlas, entre otras.

Marcela Cornejo, Escuela de Psicología Pontificia Universidad Católica de Chile.

Francisca Mendoza, Escuela de Psicología Pontificia Universidad Católica de Chile.

Rodrigo C. Rojas, Escuela de Psicología Pontificia Universidad Católica de Chile.

La correspondencia relativa a este trabajo debe ser enviada a Marcela Cornejo, Escuela de Psicología, Pontificia Universidad Católica de Chile, Vicuña Mackenna 4860 Macul, Santiago, Chile.E-mail: marcela@uc.cl

Este trabajo ha recibido financiamiento del Proyecto Fondecyt No1070855 "Del testimonio al relato de vida: procesos elaborativos en profesionales de la Comisión Nacional sobre Prisión Política y Tortura”.
Este artículo pretende visualizar momentos y aspectos de la investigación con relatos de vida que a menudo quedan escurridizos, pero que forman parte esencial del desarrollo del proceso de investigación. Se intentará articular estos momentos y decisiones tomadas durante el proceso de investigación con el marco epistemológico que las orienta y sostiene.

Se presentarán algunas premisas que sitúan el marco para la investigación desde el enfoque biográfico (De Gaulejac, 1987; Legrand, 1993; Niewiadomski \& De Villers, 2004). Posteriormente se discutirá un modelo de trabajo para el diseño de una investigación con relatos de vida, ilustrando en algunos casos distintos momentos del proceso con material de investigaciones.

\section{Premisas del Enfoque Biográfico}

En las ciencias sociales el relato de vida ha sido utilizado en varias disciplinas y con distintos objetivos: en investigación, en intervenciones o 
como una herramienta testimonial. En ese sentido, puede señalarse que el relato de vida tiene un carácter instrumental: es una técnica que puede ser utilizada con diversas finalidades. Como sucede en toda práctica, su sentido como "técnica" aparece sólo en referencia a los principios que orientan su utilización. El enfoque biográfico constituye justamente un "enfoque", una mirada orientada, en la cual cobra sentido la utilización del relato de vida: lo sitúa en un determinado marco conceptual, ético y epistemológico, que lo diferencia de su utilización bajo otra orientación.

El enfoque biográfico reúne contribuciones de distintas corrientes de pensamiento, entre ellas marxismo, existencialismo, estructuralismo, hermenéutica y psicoanálisis. Se conforma como un enfoque interdisciplinario que incluye influencias diversas: antropología, sociología, psicología, historia, educación, entre otras.

A continuación se presentarán algunas de las premisas del enfoque biográfico ${ }^{1}$, caracterizándolo como un enfoque hermenéutico (dimensión ontológica), existencial (dimensión ética), dialéctico y constructivista (dimensión epistemológica). Su elección corresponde a una opción por describir aquellas proposiciones que han ocupado un lugar relevante al momento de ejercer nuestra práctica investigativa y la reflexión sobre ésta.

\section{Un Enfoque Hermenéutico}

Cotidiana y espontáneamente, estamos siempre realizando relatos, ya sea a otros o a nosotros mismos. Estos relatos cotidianos sobre cómo nos sentimos, cómo nos definimos o sobre nuestra posición frente a determinada temática, son un primer nivel de interpretación de la experiencia que vivimos, situándola desde un "narrador" que somos nosotros mismos. Estos relatos nos definen y diferencian de otros, por lo que cumplen una función en la construcción identitaria. Se trata, según Ricœur (19831985), de una identidad narrativa, que se construye y reconstruye a través de los relatos, los cuales dan sentido a las acciones, a los eventos vividos, restituyendo un sentido global a un curso inevitablemente caótico de una existencia siempre enigmática.

Estos relatos sobre nosotros no necesariamente poseen coherencia, totalidad y estabilidad, preten-

\footnotetext{
Para una revisión más acabada sobre la trayectoria, desarrollos teóricos y perspectivas del enfoque biográfico, consultar Cornejo (2006).
}

siones que constituyen una "ilusión biográfica" (Bourdieu, 1986). En ellos existen contradicciones, tensiones y ambivalencias; las historias que nos contamos sobre nosotros poseen un carácter dinámico, cambian constantemente, pero siempre en función de otra historia que las integre y les de un nuevo sentido.

Al utilizar el relato de vida en investigación, trabajando analíticamente sobre el relato de una persona sobre sí misma o sobre un aspecto de su vida, situamos un segundo nivel de interpretación: interpretamos una producción del narrador, que a su vez, es una interpretación que hace de su propia vida.

Esta “doble interpretación” (Ricœur, 1983-1985) y los sucesivos niveles de trabajo analítico permiten introducir una distinción conceptual entre relato e historia de vida. El relato de vida corresponde a la enunciación -escrita u oral- por parte de un narrador, de su vida o parte de ella. La historia de vida, por su parte, es una producción distinta, una interpretación que hace el investigador al reconstruir el relato en función de distintas categorías conceptuales, temporales, temáticas, entre otras ${ }^{2}$.

Esta distinción muestra la consistencia de la utilización de relatos de vida como método de investigación con su propio "objeto" de estudio, en tanto siempre se trabaja con interpretaciones, en distintos niveles. Interpretaciones que se consideran constituyentes de la experiencia humana y que, por tanto, representan la dimensión ontológica del enfoque biográfico.

\section{Un Enfoque Existencial}

La puesta en palabras de la propia existencia implica una constante definición sobre aquello que somos. Sin embargo, tal como señala Heidegger (1997), muchas veces en la cotidianeidad de la vida se oculta la radicalidad que esto implica. En este caso, los seres humanos "lenguajeamos", hablamos como si lo que relatamos no nos implicara y comprometiera cada vez con nosotros mismos, a través de la posición que tomamos al enunciarlo.

En este sentido, puede afirmarse que hacerse cargo de las propias palabras, asumir la posición subjetiva desde la que hablamos, es siempre una opción ética (De Villers, 1999): podemos asumirlo o desconocerlo, elección que se pone en juego

\footnotetext{
Las definiciones de relato e historia de vida se orientan por las distinciones propuestas por Lainé (1998).
} 
cada vez, dado que nuestra existencia implica un constante contar.

Al solicitar a un narrador que nos relate su vida o parte de ella, además de la petición explícita de los contenidos que interesa investigar, existe una petición implícita: la de tomar una posición frente a lo que cuenta. El relato conlleva para el narrador una elección ineludible: optar por asumir o desconocer su posición respecto a su dicho.

Solicitando un relato de vida, se brinda la posibilidad que el narrador elija o no asumirse a sí mismo, en tanto producto, productor y actor de su historia (De Gaulejac, 1999). Reconocerse producto de una historia material (familiar, social, política, cultural) que determina su vida, condiciones en las cuales ha sido arrojado, en términos existenciales. Reconocerse productor de su historia, a través de sus propias elecciones, responsabilizándose por aquel margen de libertad que le ha permitido "hacer algo con aquello que han hecho con uno" (Sartre, 1985). A partir de estos reconocimientos, se abre la posibilidad de situarse como actor de una historia, de la cual se busca ser el protagonista.

El relato de vida muestra el dinamismo de una historia que siempre cambia al contarse: aunque no se puedan cambiar hechos del pasado, sí se puede cambiar la posición que se tiene frente a ellos desde el presente y allí radica el margen de libertad. Al advertir que la existencia se pone en juego en un presente, que se transforma, que deviene, que es esencialmente libre, se presenta entonces la opción de advenir sujeto de la propia historia (De Villers, 1999). Esta opción, que se debate al momento de la narración, representa la dimensión ética del enfoque biográfico.

Desde Lejeune (1980), el relato puede concebirse como "la puesta en escena de uno por uno", en que eventos pasados son puestos en intriga por un narrador, siempre llamado a la pregunta por el sentido y la unidad de su vida. Así, el relato permite la apropiación subjetiva de su historia, movilizando, por la resignificación de su vida, el poder de transformarse. En este sentido, el relato no es estático, y lo dicho no está dicho de una vez y para siempre. El relato está vivo, justamente porque da cuenta de un individuo también vivo, en constante cambio y transformación.

Si asumimos que la producción de un relato de vida es capaz de generar efectos en el narrador, permitiendo significar, resignificar y dar sentido a la experiencia, con las implicancias existenciales que eso conlleva, no podemos dejar de considerar dichos efectos. La solicitud que hacemos no es inocua, por tanto, es preciso cuidar las condiciones en las que se producirá esa narración: los aspectos éticos del trabajo.

Por ello, se hace fundamental delimitar claramente aquello que se busca con la producción de un relato de vida. En el caso de la investigación, las intenciones son, claro está, las de obtener un cierto conocimiento. Cuando se utiliza el relato en instancias de formación personal o profesional, ligadas al autoconocimiento, si bien las metas de comprensión y elucidación sobre la vida de alguna persona son comunes, éstas ya no se subordinan a la curiosidad de un agente externo, sino que provienen del mismo sujeto, en este caso responsable de las consecuencias y derivaciones de su narración. Se vuelve entonces fundamental cuidar los límites de la práctica investigativa, siempre en función del sujeto que tenemos en frente.

\section{Un Enfoque Dialéctico y Constructivista}

Frente a la pregunta por el sentido de la narración en la producción de un relato de vida, puede decirse que éste no pertenece ni al narrador ni al narratario ${ }^{3}$. Ninguno posee más conocimiento que el otro, sino que ambos realizan un aporte característico desde su posición, contribuyendo con una parte, complementándose (Pineau, 1992).

El narrador, por su parte, no puede poseer el sentido, irreducible a la conciencia que tiene, estando tan implicado, "corporeizado" en su propia experiencia, en lo que cuenta. En el relato el sujeto deviene su propio objeto de conocimiento, para lo cual debe distanciarse, desdoblarse simbólicamente. El narratario, en cambio, debe acercarse a las vivencias del narrador, abrirse a su lenguaje cotidiano, salir de sus propios sistemas conceptuales. Estos desplazamientos recíprocos e inversos (de distanciamiento teórico e implicación práctica) permiten la creación de un espacio y de un sistema de comunicación, de una nueva unidad, donde una parte de vida encuentra sus conceptos y unos conceptos encuentran vida (Pineau, 1992).

En la producción de un relato de vida, el narrador no es el único que habla, piensa y se transforma (Bertaux, 1993). Si asumimos que el narratario también

\footnotetext{
Utilizamos el término narratario como una traducción del término francófono narrataire, definido por De Villers (1996) como el "oyente" y como "el experto en relatos de vida" por Legrand (1999).
} 
está en juego al momento de recoger o analizar un relato, investigar, desde este enfoque implica conocer, al precio de ser conocidos. Se establece una relación sujeto-sujeto, que representa la dimensión epistemológica del enfoque biográfico y, también, se traduce en implicancias metodológicas.

En este sentido, es fundamental incluir en el análisis de los relatos de vida no sólo los contenidos que señala el narrador; en tanto el relato está siempre dirigido a alguien en ciertas circunstancias, es necesario el registro y análisis de las condiciones en que se produce ese encuentro ${ }^{4}$. Estas condiciones nunca son neutras, sino que tendrán una influencia en el contenido de lo enunciado.

El relato de vida siempre es dirigido a alguien y construido en función de lo que dicha situación de enunciación representa, de las interacciones que en ella tienen lugar y de los efectos que el narrador espera producir sobre sus destinatarios. En este sentido, es también esencial analizar el papel del narratario a través de su escucha y sus intervenciones, como también aspectos que forman parte de la dinámica transferencia-contratransferencia ${ }^{5}$ (Legrand, 1999).

Este giro implica que hay algo que se produce en la relación entre narrador y narratario, que es en sí mismo conocimiento, ya no siendo éste concebido como una verdad absoluta, ni como definido de una vez y para siempre. Tanto el lugar que ocupa el investigador en la producción del conocimiento, como el dinamismo de los fenómenos sociales que intenta comprender, tienen implicancias en la manera de comprender la producción científica.

Si los fenómenos sociales no existen por sí mismos, separados de los individuos que los viven, producen y, sufren y gozan de sus consecuencias, entonces la subjetividad cobra un valor central como vía de acceso a las dimensiones de las ciencias sociales y humanas. Lo social tiene la particularidad de jugarse en la singularidad de cada relato, en la particularidad de cada narrador, quien encarna las

\footnotetext{
4 Las "condiciones de producción" del relato abarcan elementos materiales (lugar físico del relato, tiempo disponible, condiciones climáticas), contextuales (contingencia social, política, cultural), biográficos (momento de la vida del narrador y del narratario), psicológicas (estado emocional de narrador y narratario), entre otras características que se consideren significativas para analizar ese relato.

5 Se trata de un símil (no una equivalencia) con los conceptos psicoanalíticos, comprendiendo que el marco conceptual y el encuadre que permiten la lectura de estos fenómenos, como se formulan en psicoanálisis, sólo son posibles en la sesión psicoanalítica.
}

tensiones de un determinado momento, en un determinado lugar, en ese presente.

En la práctica, las premisas del enfoque biográfico se traducen en opciones metodológicas en distintos momentos de la investigación. Inevitablemente, la forma en que concebimos la realidad y al ser humano inspirará el modo en que miramos y nos situamos frente a nuestro "objeto de estudio". A continuación se presenta un modelo de trabajo para el diseño de investigaciones con relatos de vida, discutiendo opciones de trabajo en base a material de investigaciones.

\section{Un Modelo de Trabajo para el Diseño de Investigaciones con Relatos de Vida}

Más allá de los componentes esenciales obligados en una investigación (diseño, recolección, análisis, publicación de resultados), existen innumerables variaciones posibles respecto a cómo implementar una investigación desde el enfoque biográfico utilizando relatos de vida. Su anclaje disciplinar, cuestionamientos científico-epistemológicos o bien ético-ontológicos, son insoslayables y es necesario reflexionar en torno a ellos en el proceso de la investigación.

Un modelo de trabajo que hemos utilizado y afinado en nuestras investigaciones, recoge la propuesta hecha por Michel Legrand (1993) sobre el relato de vida de investigación, propuesta que va desarrollando los desafíos, tareas e implicancias contenidas en cada una de las etapas de la investigación. Retomaremos y comentaremos cada una de estas etapas, discutiendo nuestras propias opciones de trabajo, ilustrándolas con dos de nuestras investigaciones, una sobre la experiencia del exilio chileno y su incidencia en la construcción de la identidad (Cornejo, en prensa) y otra sobre la experiencia de recepción de testimonios de prisión política y tortura en una comisión de verdad y reparación recientemente implementada en Chile (Cornejo, Morales, Kovalskys \& Sharim, 2006; Cornejo, Rojas \& Mendoza, 2007).

\section{Antes de la Recolección}

Previo a comenzar la etapa de la recolección de datos, viene un momento importante en el que se definen aspectos centrales que guiarán todo el proceso de recolección y análisis de los datos $\mathrm{y}$, sentarán las bases fundamentales de la investigación que se realiza. En esta etapa se deben discutir y afinar aspectos relativos a la pregunta de investigación (lo 
que incluye el tema y el foco que se le dará), a la relación del investigador con ese tema y, finalmente, a las bases conceptuales y teóricas que articularán y orientarán la investigación.

Según Legrand (1993), antes de comenzar la recolección del primer relato, el investigador debe, al menos, realizar dos elecciones ineludibles: el tema de la investigación y el ángulo de ataque de ese tema, una pregunta fundamental hacia éste.

La especificidad del método se definirá por el abordaje del tema, bajo la perspectiva de la historia de vida. En este sentido, es importante considerar que no todos los temas de investigación son abordables desde el punto de vista de la biografía o la narración de la historia de vida. Como tampoco, no todos los ángulos de ataque de determinados temas suponen un abordaje donde la utilización de los relatos de vida sea lo más pertinente.

Es necesario tomar en cuenta que la biografía no es ni social, ni física, ni subjetiva, sino que es todo al mismo tiempo, unido en una totalidad compleja y original. En este sentido, el relato de vida debe ser considerado como el estudio del modo en que un fenómeno se constituye biográficamente en la forma del individuo.

Pero con estos dos puntos resueltos, no se estaría aún necesariamente preparado para la recolección de los relatos, esto, porque nunca se es neutro, sin una relación previa en cuanto al tema que se quiere investigar. Dos operaciones se imponen a ser realizadas: una puesta en disposición clínica y una preparación teórica.

Legrand (1993) sugiere sostener, en lo posible a lo largo de todo el proceso de la investigación, una puesta en disposición clínica que trabaje sobre el vínculo previo con el tema a investigar y que intente dilucidarlo: ¿Por qué la elección del tema? ¿Por qué investigarlo? ¿Para qué investigarlo? ¿El interés surge de una experiencia personal? ¿Cuál?

En lo práctico, hemos desarrollado en nuestras investigaciones varios dispositivos para intentar trabajar y poner la subjetividad de los investigadores al servicio de la investigación. Más adelante volveremos sobre ellos.

En cuanto a la preparación teórica, esta adquiere en general la forma de una revisión crítica de la literatura científica pertinente al tema, orientada a aumentar las potencialidades de la investigación, dotándose de un bagaje conceptual que profundice la comprensión del objeto de estudio.

En las investigaciones que desarrollamos, un aspecto importante ha sido que la búsqueda y revisión crítica de la literatura pertinente al tema investigado no se ha circunscrito sólo al inicio de la investigación, sino que ha sido un proceso mantenido en el curso de la misma, de manera que la recolección de relatos y su análisis permite la emergencia de nuevas pistas que deben ser seguidas también a nivel de literatura especializada.

\section{Contactos, Negociaciones, Contratos}

Una vez construido nuestro objeto de estudio, iniciado el proceso de puesta en disposición clínica y orientada la preparación teórica, es necesario diseñar la forma y procedimientos que se utilizarán para contactar y convocar a potenciales participantes.

En la fase de contacto, los cuestionamientos éticos se vuelven fundamentales, entrecruzándose con cuestionamientos científicos. Definir criterios respecto a qué sujetos convocar, cómo contactarlos, al tipo de información que les entregaremos, a la información incluida en el consentimiento informado, se hace necesario realizar de manera reflexionada y velando en cada momento por la coherencia de la investigación y la ética que todo proceso investigativo debe cuidar.

\section{Los Participantes}

Junto con definir al inicio los criterios de inclusión y exclusión, también es necesario considerar que, dado que el objeto de estudio se irá reconstruyendo a medida que avanza el proceso de investigación, el muestreo se guiará en función de cómo avancen y se vayan desarrollando los análisis realizados.

Respecto a cuántos narradores convocar, las decisiones serán en gran parte determinadas por las características, propósitos y orientaciones particulares de cada investigación, así como por criterios relativos al tiempo disponible para realizar la investigación. Sin embargo, es importante determinar al inicio un número limitado pero relativamente indeterminado y reevaluar a medida que la investigación avanza. De acuerdo a nuestra experiencia y la de otras investigaciones, no debería pensarse en un número inferior a 12 participantes.

\section{La Lógica de los Encuentros}

Es importante dirigirse a los potenciales participantes de la investigación entregándoles información tanto en lo referido al contenido y objetivos de la investigación, como respecto a las modalidades y 
procedimientos que implicará su participación. Hay que comunicarle al participante que nos interesa comprender el lugar que ha ocupado y el sentido que ha tenido un hecho en su historia de vida, la cual intentaremos reconstruir con él.

Respecto a las modalidades de trabajo, es importante adelantar que requerimos grabar los encuentros dada la forma en que trabajaremos. Asimismo hay que explicar cuál será el encuadre específico del dispositivo: cuántos encuentros, su duración, cada cuánto tiempo, entre otras.

La manera en que hemos contactado a los potenciales participantes también debe quedar clara porque entrega informaciones acerca de cuánto sabemos respecto a su vida.

Entregar la información necesaria es importante, además, porque nos parece portador de un mensaje ético en relación a la manera de concebir y de hacer en la investigación: son los participantes los “expertos", que tienen los conocimientos y las informaciones que necesitamos y no a la inversa.

\section{El Consentimiento de los Participantes}

La investigación con relatos de vida aboga por la importancia del consentimiento informado de los participantes y de tener presente la libertad que tiene el sujeto frente a la propuesta realizada, la cual puede rechazar en todo momento.

Los principales aspectos contenidos en el consentimiento informado dicen relación, como en otras investigaciones, con las principales características y requerimientos de la participación, así como con aspectos relativos a la confidencialidad, anonimato y la posibilidad del participante de retirarse en cualquier momento de la investigación sin que esto tenga consecuencia alguna.

El relato de vida no funciona si el sujeto no se apropia de la consigna, si no tiene un rol activo en el proceso de recolección de los relatos. Tampoco, si siente que está en alguna forma obligado o forzado. Clarificar y destinar tiempo a informarlo es en este sentido esencial. La sensación de participación libre tiene un efecto evidente sobre el desarrollo de los encuentros, su ambiente distendido, la relación fluida con el investigador y las maneras "comprometidas" de narrar de los participantes.

\section{La Presentación de los Investigadores}

Otro aspecto importante a considerar en esta fase, es la presentación que se hará del investigador y de su equipo. Es necesario explicitar a los poten- ciales sujetos participantes o a las personas que nos contactarán con ellos, de la manera lo más clara posible, que somos investigadores, pertenecientes a cierta institución, trabajando sobre un tema y necesitados de la colaboración de personas directamente implicadas por esto en sus vidas. En este punto es preciso explicar a los sujetos cómo es que hemos llegado hasta ellos.

La relevancia de presentarse como investigadores, no tiene solamente un interés por la transparencia, sino además permite aclarar que el rol que convoca no es brindar una atención de tipo terapéutico. Resulta necesario tomar estas precauciones para que la persona no ponga al investigador en el lugar de ayuda ni corra riesgos por el hecho de reencontrarse con su propia historia.

El relato de vida siempre debe estar subordinado a una intención y un encuadre de investigación. Sin embargo, su práctica pone en juego una implicación fuerte del sujeto, quien es invitado a reactualizar y a remover una historia personal a veces dolorosa, en el contexto de una relación interpersonal íntima, que supone una escucha cálida y empática.

En las investigaciones que hemos realizado, se han tratado temas vinculados con lo que fue la época de la dictadura en Chile. En este sentido, subsisten aún desconfianzas y la necesidad imperativa de situar al otro en relación a ciertos criterios de clasificación social y política. En los dos casos, el hecho que se nos haya relacionado con ciertos criterios, ha permitido que las personas hayan estado dispuestas a contarnos su historia y a profundizar en ciertos aspectos.

\section{Enfrentarse al Sufrimiento}

Otro aspecto al que hay que prestar atención antes de ir al terreno, es al hecho que trabajar con relatos de vida conlleva que los participantes se impliquen y se comprometan fuertemente con sus historias, re-observándolas, examinándolas, conmoviéndose y reactualizando sus sufrimientos, respecto a momentos particularmente difíciles y dolorosos. Esto determina momentos muy fuertes desde el punto de vista afectivo y del involucramiento de los participantes y de los propios investigadores.

En ambos casos que aquí relatamos, nuestras investigaciones suponían experiencias marcadas por una fuerte carga afectiva. Por otro lado, dado que se trata de temas relativos a la dictadura en los que en general se ha impuesto un silenciamiento individual y social, el hecho de ofrecer un espacio para su na- 
rración podía resultar potencialmente fragilizador para quien contaba su historia.

Es necesario tener claridad en establecer un marco de escucha en una relación interpersonal íntima (cercana, cálida, empática) pero que comienza y termina siempre dentro de los límites de la investigación. En este sentido, en ambas investigaciones contactamos a colegas terapeutas a los cuales poder, eventualmente, derivar a algún participante para quien la narración de su historia pudiera haber hecho emerger síntomas y/o dificultades emocionales latentes y que requerirían de algún apoyo específico que sobrepasara la instancia y los límites de una investigación. Hasta acá estas alternativas de derivación no han sido necesarias.

Cabe señalar, en este sentido, la importancia de una formación en relatos de vida y en el enfoque biográfico que no sólo sea teórica; la experiencia de haber sido uno mismo narrador favorecerá poder enfrentar estas situaciones y recoger informaciones que sean de calidad. Así también, el hecho de trabajar en equipo, permite que puedan incorporarse diversas miradas cuando situaciones como éstas se presentan, lo que favorece el resguardo del narrador.

\section{La Recolección de los Relatos: las Entrevistas}

Es interesante a la hora de trabajar con relatos de vida, tener clara la idea que los relatos de vida no son ni la vida misma, ni la historia misma, sino una reconstrucción realizada en el momento preciso de la narración y en la relación específica con un narratario. Los relatos de vida serán entonces siempre construcciones, versiones de la historia que un narrador relata a un narratario particular, en un momento particular de su vida.

En este sentido, la narración que un sujeto haga estará irremediablemente afectada por influencias contextuales actuales, tanto de la vida del narrador como la del narratario, y por influencias relativas al particular encuentro entre ese narrador y ese narratario para contar esa historia.

Cada uno de los contactos previos de reclutamiento así como los encuentros con cada narrador deben ser cuidadosamente preparados. Cómo éstos se desarrollen servirá de soporte para la narración que los participantes realicen y contendrán además información relativa a la producción de los relatos que es importante de considerar al momento de los análisis de las informaciones surgidas.

Es importante construir una relación particular y específica con cada narrador, la que estará deter- minada por las características personales de cada uno y por las implicancias que estas características determinan recíprocamente en el narrador. Un relato permitirá el despliegue de una historia de vida en la medida en que el narrador se sienta en confianza, de forma que establezca su propio pacto autobiográfico (Lejeune, 1975) y acepte hablar en un dispositivo de escucha propuesto, como si lo controlara, cuando en último término no puede hacerlo.

De acuerdo a nuestra experiencia en las investigaciones que desarrollamos, la preocupación y desarrollo de las relaciones de entrevista que construimos con los participantes en la recolección de sus relatos, también confirma las virtudes del tipo de relaciones construidas en el marco del enfoque biográfico, en lo que concierne las múltiples rupturas respecto de las formas más tradicionales de investigación: mayor igualdad, mayor paridad y mayor co-construcción en los conocimientos.

\section{El Procedimiento de las Entrevistas}

Revisaremos algunos aspectos puntuales referidos al desarrollo mismo del proceso de recolección de relatos con cada narrador, en particular a las especificaciones del dispositivo de escucha.

El número de entrevistas. El narrador es más que un informante, es un sujeto interpelado en su historia. En esto recae la necesidad de realizar una elaboración a través del relato, que demanda un mínimo de tiempo y que exige una pluralidad de encuentros que permitan retomar estas reflexiones.

En la investigación sobre el exilio (Cornejo, en prensa) optamos por un dispositivo de 2 encuentros. Sin embargo, sentimos que no fue suficiente, que el impulso en la narración y elaboración de la historia era abruptamente cortado en el segundo encuentro en donde además se debía realizar el cierre del proceso. Es por esto que en la investigación con los profesionales de la Comisión implementamos un dispositivo que incluye 3 encuentros, y que permite un despliegue de la narración y una inmersión en la historia que posibilita tanto a narrador como a narratario profundizar en la historia y su narración, a través de la construcción de una relación que sostiene esta historia que se construye.

La forma que adquiera cada dispositivo debe estar en coherencia con el objetivo y orientación general de cada investigación. En cualquier caso, aconsejamos varios encuentros de modo de darle al relato un espesor reflexivo. Así mismo, es aconsejable definir e informar a cada participante desde 
un principio cuántos encuentros contemplará su participación, de modo a que pueda decidir informadamente.

En este punto como en otros, es importante también ser flexibles en el sentido de poder adaptar las características del dispositivo ante situaciones particulares que así lo ameriten.

El dispositivo que desarrollamos actualmente (Cornejo, Rojas \& Mendoza, 2007) considera un primer encuentro que abre la narración y despliega los temas que trae el narrador; un segundo encuentro en donde introducimos preguntas de profundización; $y$ un tercer encuentro definido siempre como un encuentro de cierre, tanto de la narración de la historia como de la relación de escucha establecida entre narrador y narratario, así como de evaluación del proceso de participación en la investigación.

Los encuentros dos y tres son iniciados además con preguntas respecto a lo que ha significado para el narrador contar su historia y leer las transcripciones.

Transcripción de las entrevistas. Nuestros dispositivos han incluido la grabación de los encuentros previa autorización de los narradores y la entrega de las transcripciones entre cada encuentro al narrador de manera a que pueda revisarlo y volver sobre él en el encuentro siguiente.

Los relatos son transcritos en su totalidad, conservando en lo posible toda su riqueza en las transcripciones, las faltas de lenguaje, lapsus, titubeos, modismos, así como los silencios o pausas de los narradores en ciertos pasajes del relato. La decisión de editar o no las transcripciones para ser entregadas al narrador, deberá fundamentarse en las opciones metodológicas y epistemológicas de cada investigación. Nuestra opción ha sido conservar la transcripción lo más fiel posible, sin editarla. Una edición, sin embargo, es realizada al momento de someter el material para su análisis ya que son modificados aspectos (nombres de lugares, personas, entre otros) que pudieran hacer reconocibles a los narradores.

El ritmo de las entrevistas. El intervalo entre los encuentros también debe ser determinado desde un principio e informado a los participantes. Este tiempo debe considerar la transcripción del encuentro, su análisis preliminar preparando el encuentro siguiente $y$, de parte del narrador, la lectura de la transcripción, la toma de distancia de su relato y de su historia y una cierta elaboración. Así mismo, este intervalo debe permitir que se mantenga una cierta continuidad en el proceso de inmersión y narración de la historia.
Considerando lo anterior, un intervalo de 15 días parece razonable, teniendo en cuenta que puede ser modificado debido a imprevistos del narrador o del narratario.

Duración de las entrevistas. En general, se estima entre una hora a una hora y media cada encuentro. Es una duración que permite que tanto narrador como narratario puedan mantener su capacidad de escucha, uno, y la producción de un material rico, el otro. Sin embargo, la particularidad de la duración de cada encuentro estará determinada por la dinámica específica y el tipo de relación que se construya con el narrador.'

La conducción de las entrevistas. Las entrevistas deben ser conducidas a la luz de los criterios de la nodirectividad: una escucha calurosa, una comprensión empática y una neutralidad benévola (Lainé, 1998; Legrand, 1993).

Es importante reflexionar en torno a la consigna inicial que dará inicio a la narración ya que es portadora de un mensaje con el cual el narrador se queda para dar inicio a la historia que va a contar. Dado que hemos realizado relatos de vida temáticos, es decir, que abordan un aspecto específico de la historia de los narradores, hemos optado por entregar consignas iniciales amplias y generales, que otorguen libertad a los narradores para estructurar su relato desde y hacia donde ellos prefieran hacerlo. El uso de consignas amplias, se fundamenta en la opción ética de que sea el narrador quien asuma un rol principal, como sujeto agente y responsable de su propio relato.

A medida que los encuentros se desarrollan, se incluyen preguntas de profundización, que apuntan a la clarificación de informaciones incompletas respecto a ciertos momentos de la historia, la precisión de ciertas fechas y se invita a retomar ciertos pasajes o personajes de la historia. Estas preguntas deben estar orientadas, para cada caso, siguiendo la lógica singular y son definidas en función del análisis de la historia y del relato.

\section{Dispositivos de interanálisis}

Un aspecto central en el trabajo con relatos de vida tiene que ver con las condiciones de producción de éstos. Siendo como vimos el relato de vida una construcción, estas condiciones de producción debieran ser consideradas al momento de trabajarlos, es decir, en las etapas relativas a su recolección, análisis e interpretación. 
Como una manera de incluir estas condiciones de producción, hemos desarrollado dispositivos de interanálisis que apuntan a diversos aspectos, muchos de ellos en relación con la subjetividad de la interacción narrador/narratario que sostiene y construye el relato, y que han permitido su incorporación al servicio del análisis de los datos.

La utilización de un cuaderno de campo del narratario, ha tenido como función principal acompañar el proceso de recolección de los relatos así como de los análisis que se van realizando en esta etapa. Un modelo que utilizamos (Cornejo, en prensa) se orientó, al término de cada sesión con cada narrador, a responder tres preguntas: ¿Quién está contando esta historia? ¿Quién está escuchando esta historia? ¿Qué historia se está escuchando?

Inspirados en los trabajos de Danneau (1988) y de Cornejo (2004), se planteó la necesidad en el análisis de los relatos de una "tercera persona exterior", que leyera el relato y acompañase el proceso de recolección y análisis. A partir de esto, se constituyeron al interior del equipo de investigación (Cornejo et al., 2006), duplas de trabajo para la recolección y los análisis. Estas duplas trabajaron para cada narrador en aspectos como el proceso mismo de contar y escuchar la historia relatada; los contenidos específicos en relación a la temática investigada; y finalmente aspectos relativos a la preparación del encuentro siguiente con ese narrador. Estas informaciones se sistematizaron en un dossier que apoyó el trabajo de recolección y análisis para cada narrador.

\section{El Análisis de los Relatos}

Dentro del enfoque biográfico, diversos autores señalan que no existe un método único para el análisis de los datos (Lainé, 1998, Legrand, 1993). Más bien, los métodos se definen en consideración de los objetivos de la investigación, del fenómeno estudiado y de ciertas consideraciones epistemológicas y metodológicas acerca de la construcción de conocimiento científico, planteando una diversidad de posibilidades (Bertaux, 2005; Cornejo, 2006; Kornblit, 2004; Legrand, 1993).

Una revisión de la literatura permite encontrar al menos las siguientes propuestas de análisis para relatos de vida: el análisis clínico (Sharim, 2005); la hermenéutica colectiva (Molitor, 2001); un modelo basado en el análisis actancial de Greimas (De Villers, 1996); el análisis del sí mismo (Piña, 1988); el análisis de la sociología clínica (De Gaulejac, 1987, 1999); el análisis de la identidad (Demazière \& Dubar, 1997), entre otros.
En esta diversidad, en nuestras investigaciones hemos utilizado por un lado, diversas lógicas de análisis para las historias de los narradores, y por otro, diferentes métodos de análisis para cubrir en la mayor profundidad y riqueza las informaciones provenientes de un tipo de material cualitativo discursivo, como lo es un relato de vida.

Respecto a las lógicas de análisis, se ha privilegiado en un primer momento la singularidad y la particularidad de cada historia relatada, intentando ser fieles a una de las premisas fundamentales del enfoque biográfico. En este sentido, se plantea una lógica singular, intracaso, en la que se analiza y trabaja en profundidad cada historia relatada. La idea es poder llegar a una historia reconstruida, a partir del análisis de la escucha de la historia y de los principales hitos biográficos que constituyen la vida del narrador.

En un segundo momento, se ha adoptado una lógica transversal, inter-caso, que permite, a partir de ciertas continuidades y discontinuidades de la fase singular, determinar ejes temáticos-analíticos relevantes e hipótesis comprensivas transversales, para abordar el fenómeno en estudio. A partir de estos ejes temáticos-analíticos, se vuelven a analizar todas las historias, desde la óptica de la transversalidad que las recorre en su conjunto.

Respecto a los métodos de análisis, se ha trabajo articulando diferentes métodos para cubrir tanto los contenidos que emergen de las historias (análisis de contenido de material discursivo) así como la estructura de la narración en que se expresan (análisis de discurso).

Es importante señalar finalmente respecto al análisis de los relatos que será siempre necesario adaptar lógicas y métodos de análisis en función, por un lado, del tipo de resultados que se deseen obtener, y por otro, considerando que el objeto de estudio debe ser quien manda, esto es que los métodos de análisis pueden adaptarse a él pero nunca al revés.

\section{Discusión}

En general, la literatura sobre investigación con relatos de vida se ha centrado o bien en las bases teóricas o bien en los resultados de las investigaciones. Este artículo ha tenido por objeto visibilizar aspectos operativos situados entre ambos, instalando una reflexión sobre el proceso de pensar cómo investigar con relatos de vida.

El relato de vida es una técnica que puede utilizarse de forma creativa, pero que requiere de un encuadre del que emerja su sentido y le otorgue rigurosidad. En este sentido, la utilización del enfoque biográfico conlleva numerosas implicancias metodo- 
lógicas. En particular, sus dimensiones ontológica, ética y epistemológica han orientado nuestra práctica investigativa, iluminando importantes decisiones que no debieran pasar desapercibidas.

\section{Implicancias de la Práctica Biográfica}

La investigación con relatos de vida es sincera en tanto no busca dar una ilusión de verdad o certeza, sino que acepta la incertidumbre e impredictibilidad de la vida, sin pretender que seamos seres epistemológicamente objetivos cuando somos ontológicamente subjetivos. Se trata, finalmente, de acercarse a un sujeto complejo (Rhéaume, 1999), con sus determinaciones (sociales, físicas, psicológicas, históricas, materiales) y su libertad existencial, lo que promueve una aproximación consistente con esta complejidad.

Las decisiones metodológicas que tomamos durante la investigación no son inocuas, sino que competen y afectan a quien tenemos en frente, dispuesto a darnos su relato de vida. Es por ello que deben estar siempre orientadas reflexivamente, en atención a nuestros narradores.

En primer lugar, es importante considerar qué haremos con la técnica del relato de vida y hasta dónde llegaremos en su utilización. La pregunta acerca de la pertinencia de nuestras intenciones y rangos de acción se torna fundamental. Por un lado, la solicitud de un relato a un determinado narrador deberá ajustarse y justificarse en base a ciertas temáticas, preguntas y objetivos de la investigación, siendo el narrador una fuente de información relevante para los fines investigativos. Por otro lado, no se debe olvidar el cuidado ético de los participantes, en relación a las implicancias de entregar su relato. En este sentido, un potencial narrador puede ser un informante clave, pero no estar en un momento o condiciones favorables para la emisión de un relato de vida. ¿Es este un narrador adecuado? ¿Es el relato de vida la técnica adecuada para este narrador? Son preguntas que no pueden ser omitidas, si consideramos que no son solamente ganancias para la investigación las que están en juego al momento de solicitar a alguien su relato.

En segundo lugar, desde el enfoque biográfico, serán siempre las técnicas y el dispositivo los que deben adaptarse a la singularidad de cada narrador, siendo el sujeto de estudio quien manda. En la práctica, esto se traduce en la generación de condiciones y garantías para desarrollar el relato de vida; en pensar en el ritmo y frecuencia de los encuentros y en el rol del narratario (margen de acción de sus intervenciones, señalamientos e interpretaciones).

Una tercera implicación tiene que ver con la necesidad e importancia de las instancias de formación de los investigadores. Es importante contar, durante la recolección, con instancias de interanálisis, al modo de supervisiones. Estas permiten discutir y profundizar acerca de la relación que se establece con cada narrador, de sus implicancias para narrador y narratario, así como orientar de modo asertivo el manejo de los posteriores encuentros. Se vuelven también esenciales la formación teórica y práctica del investigador y un trabajo personal que permita conocer la experiencia de relatar, de haber estado del otro lado.

\section{La Investigación como Práctica Ideológica}

Consistente con los planteamientos expuestos, puede señalarse que la epistemología, en tanto opción sobre cómo conocer la realidad, se sostiene entrelazada a una apuesta ontológica (forma de concebir la realidad) y ética (cómo situarse frente a esa realidad). Desde la posición ontológica, ética y epistemológica del enfoque biográfico, puede asumirse que su práctica (y en general, podríamos pensar, toda práctica investigativa) es necesariamente ideológica: la implicación del investigador en aquello que investiga es ineludible.

Si asumimos que siempre se investiga por algo y para algo; si la subjetividad del investigador siempre está en juego al momento de investigar, en vez de ser desprestigiada, esta subjetividad puede ser utilizada al servicio de la investigación, como lo representa la puesta en disposición clínica.

La investigación también es ideológica en tanto no está suspendida sino que siempre situada en su contexto social, del cual surge y al cual retorna. La investigación es una práctica orientada, en tanto no sólo tiene la exigencia de conocer y comprender la realidad en que se inserta, sino que pretende impactar en los distintos ámbitos sociales, al poner temas en la agenda pública, al brindar nuevas miradas a fenómenos ya estudiados. En este sentido, consabido es el carácter emancipador de las prácticas biográficas (Pineau \& Le Grand, 1993), al contribuir a dar la palabra a ciertos actores sociales y sus temáticas particulares.

Por esta razón, definir qué se investiga cuando se investiga desde lo biográfico, supone la puesta en juego de una opción ideológica y política. Se 
considera muy relevante, entonces, el asumir estas opciones y hacerlo de una manera reflexiva y crítica. Es la ética, en tanto un posicionamiento particular desde las elecciones que se realizaron, la que fundamenta el carácter de las prácticas de las ciencias, en especial de las que se denominan sociales, humanas y clínicas.

Este artículo es una invitación a visibilizar y reflexionar sobre decisiones metodológicas cuya importancia puede pasar fácilmente desapercibida en investigación. A fin de cuentas, las opciones relativas al enfoque teórico y el trasfondo epistemológico de una investigación no conforman una primera etapa separada del desarrollo de ésta, sino que se juegan y debaten en la práctica misma, y en el caso del trabajo con relatos de vida, en la relación que se establece con cada narrador.

Existen muchas maneras posibles de realizar investigación y de utilizar el relato de vida, siempre y cuando su elección se sustente en un proceso reflexivo que acompaña todo el proceso investigativo. Si bien la investigación cualitativa se caracteriza por estar siempre abierta a ajustes en su dispositivo de recolección y otros aspectos metodológicos, se trata de una "flexibilidad orientada" que garantice la rigurosidad y otorgue riqueza a los datos, y no de mera improvisación.

\section{Referencias}

Bertaux, D. (2005). El análisis de un relato de vida. En D. Bertaux, Los relatos de vida. Perspectiva etnosociológica (pp. 73-102). Barcelona: Edicions Bellatera.

Bertaux, D. (1993). De la perspectiva de la historia de vida a la transformación de la práctica sociológica. En C. Santamarina \& J. M. Marinas, La historia oral: Métodos y experiencias (pp. 19-34). Madrid: Debate.

Bourdieu, P. (1986). L'illusion biographique. Actes de la recherche en sciences sociales, 62-63, 64-72.

Cornejo, M. (2006). El enfoque biográfico: Trayectorias, desarrollos teóricos y perspectivas. Psykhe, 15, 95-106.

Cornejo, M. (en prensa). Political exile and the Construction of Identity: A life stories approach. Journal of Community \& Applied Social Psychology.

Cornejo, M., Morales, G., Kovalskys, J. \& Sharim, D. (2006). Del testimonio al relato de vida: Procesos elaborativos de los profesionales de la comisión Nacional sobre Prisión Política y Tortura”. Proyecto de Investigación FONDECYT 1070855.

Cornejo, M., Rojas, R. C. \& Mendoza, F. (2007). The experience of the professionals of the National Commission on
Political Imprisonment and Torture. Manuscrito sometido para publicación.

Daneau, A.-M. (1988). Romans personnels, traits d'histoires communes: Trois récits de vie sur la maladie mentale. Memoria no publicada, Université catholique de Louvain.

De Gaulejac, V. (1987). La névrose de classe. Paris: Hommes et Groupes Éditeurs.

De Gaulejac, V. (1999). Historias de vida y Sociología Clínica. Proposiciones, 29, 89-102.

De Villers, G. (1996). L'approche biographique au carrefour de la formation des adultes, de la recherche et de l'intervention. Le récit de vie comme approche de recherche-formation. En D. Desmarais, \& J. M. Pilon (Coord.). (1996). Pratique des histoires de vie (pp. 107-134). Paris: L'Harmattan.

De Villers, G. (1999). La historia de vida como método clínico. Proposiciones, 29, 103-114.

Demazière, D. \& Dubar, C. (1997). Analyser les entretiens biographiques. L'exemple de récits d'insertion. Paris: Nathan.

Heidegger, M. (1997). Ser y Tiempo (Traducción de Jorge Rivera). Santiago: Editorial Universitaria

Kornblit, A. L. (Coord.) (2004). Metodologías cualitativas en ciencias sociales. Buenos Aires: Editorial Bilblos.

Lainé, A. (1998). Faire de sa vie une histoire. Théories et pratiques de l'histoire de vie en formation. Paris: Desclée de Brouwer.

Legrand, M. (1993). L'approche biographique. Paris: Hommes et perspectives - Desclée de Brouwer.

Legrand, M. (1999). La contra-transferencia del investigador en los relatos de vida. Proposiciones 29, 115-121.

Lejeune, $\mathrm{Ph}$. (1975). Le pacte autobiographique. Paris: Editions du Seuil.

Lejeune, Ph. (1980). Je est un autre. Paris: Editions du Seuil.

Molitor, M. (2001). Sobre la hermenéutica colectiva. Revista Austral de Ciencias Sociales, 5, 3-14.

Niewiadomski, C. \& De Villers, G. (Eds.) (2002). Souci et soin de soi. Liens et frontières entre histoires de vie, psychothérapie et psychanalyse. Paris: L'Harmattan.

Pineau, G. (1992). Dialectique des histories de vie. En D. Desmarais \& P. Grell (Eds.), Les récits de vie. Théorie, méthode et trajectoires types (pp. 131-150). Montréal: Editions Saint Martin.

Pineau, G., \& Le Grand, J.-L. (1993). Les histoires de vie, collection Que-sais-je? Paris: PUF.

Piña, C. (1988). La construcción del "sí mismo" en el relato autobiográfico. Santiago: FLACSO-CHILE.

Rheaume, J. (1999). La aproximación clínica en las Ciencias Humanas. Proposiciones, 29, 122-127.

Ricœur, P. (1983-1985). Temps et récit. 3 tomes. París: Editions du Seuil.

Santamarina, C. \& Marinas, J. M. (1993). La historia oral: Métodos y experiencias. Madrid: Debate.

Sartre, J. P. (1985). El existencialismo es un humanismo. Buenos Aires: Ediciones del '80.

Sharim, D. (2005). La identidad de género en tiempos de cambio: Una aproximación desde los relatos de vida. Psykhe, 14, 19-32.

Fecha de recepción: Noviembre de 2007.

Fecha de aceptación: Enero de 2008. 